\title{
Impactos da lei 8.630 sobre a infra-estrutura de terminais de contêineres e na viabilização da navegação de cabotagem no Brasil
}

\author{
Renata Ervilha'; Edson José Dalto²; Alberto Félix Suertegaray ${ }^{3}$
}

\begin{abstract}
Resumo: Com a reforma da legislação portuária e o processo de privatização dos portos, os terminais públicos marítimos passaram por significativa reestruturação. O elevado investimento e a simplificação da lei propiciaram o aumento de produtividade e de segurança e redução das tarifas. A melhoria nos terminais de contêineres viabilizou a consolidação da navegação de cabotagem de carga geral, como alternativa de transporte rodoviário. Estas mudanças trouxeram novas perspectivas na prestação de serviço por parte dos armadores, no sentido de atender plenamente as necessidades de transportes dos embarcadores, através de um serviço logístico completo porta-a-porta, como alternativa ao transporte porto-a-porto, incluindo a oferta de transporte multimodal, estufagem de contêineres e armazenagem. São ainda apresentados dois exemplos práticos de transporte de resinas no sentido norte-sul e de arroz, no sentido oposto, ilustrando como as mudanças no setor favoreceram a migração do transporte rodoviário para o marítimo.
\end{abstract}

\begin{abstract}
With the changing on port legislation and privatization process in Brazilian ports, the maritime public terminals passed trough an important restructuring. The expressive investment and simplification on law brought productivity and security improvement and reduced fees. The enhancement on container terminals enabled strengthening of cabotage navigation as an alternative to road transportation. These changes brought new perspective on service offered by shipowners, in a sense of attending the fully transport necessities of the shippers, by a complete logistic service door-to-door, as alternative to a port-to-port transportation, including the multimodal transport offering, container filling and wholesaling. It is so introduced two practical examples of transportation of gum, over the north-south bound and rice over the opposite direction, illustrating how changes on the sector favored the migration from road transport to maritime one.
\end{abstract}

\section{INTRODUÇÃO}

Ao longo dos anos, com o aumento do comércio que trouxe a abertura dos mercados internacionais, a logística passou a ser tratada estrategicamente nos países e dentro das empresas, no sentido de oferecer integração e coordenação aos serviços relativos a transporte e armazenagem de mercadorias, desde a aquisição da matéria-prima até a entrega do produto final. O modelo mais lógico para o Brasil, um país de dimensões continentais e com 9 mil km de costa, seria vencer longas distâncias com a ajuda dos modais aqüaviário e ferroviário. No entanto, pelo histórico de falta de investimentos em portos e ferrovias, tais modais pouco se desenvolveram antes do processo de privatização. Como conseqüência, cresceu o uso do modal rodoviário, distorcendo a matriz brasileira em relação à lógica dos modelos de transportes (Souza, 2004).

Segundo especialistas de transportes que participaram da Pesquisa de Previsão Delphi, entre

\footnotetext{
${ }^{1}$ Renata Ervilha, Faculdades Ibmec/RJ. Rio de Janeiro, RJ, Brasil (e-mail: renata.ervilha@cvrd.com.br).

${ }^{2}$ Edson José Dalto, Faculdades Ibmec/RJ. Rio de Janeiro, RJ, Brasil (e-mail: edalto@ibmecrj.br).

${ }^{3}$ Daniel Ramos Victorino, Faculdades Cândido Mendes. Rio de Janeiro, RJ, Brasil (e-mail: afsuerte@yahoo.com.br).
}

Manuscrito recebido em 19/10/2007 e aprovado para publicação em $2 / 6 / 2008$. Este artigo é parte de TRANSPORTES, volume XVI, número 1 , de junho de 2008. ISSN: 1415-7713.
1992 e 1993, as principais razões para a redução da cabotagem foram a ineficiência e a obsolescência do sistema portuário brasileiro, os elevados custos das operações portuárias, a falta de navios especializados, a rígida legislação trabalhista, a concentração dos investimentos em infra-estrutura rodoviária e as elevadas taxas de inflação no fim da década de 80 (Fadda, 1998).

$\mathrm{O}$ processo de privatização da infra-estrutura portuária, acompanhado da modernização da legislação, com a promulgação da Lei 8.630/93, conhecida com Lei de Modernização dos Portos, trouxe nova realidade e boas oportunidades às empresas, alterando substancialmente a estrutura do setor de transporte marítimo, no que diz respeito a investimentos, tecnologia, relações trabalhistas e condições operativas. O desafio, hoje, passa por investigar e analisar as diversas opções de modais e possíveis combinações entre eles, e definir a melhor alternativa de transporte e logística com base no trade-off entre custo e qualidade.

Este estudo analisa o impacto da nova legislação portuária e privatização de terminais sobre $\mathrm{o}$ funcionamento do sistema de transporte marítimo e, particularmente, sua influência na retomada da navegação de cabotagem de carga conteinerizada e no incentivo ao transporte multimodal. A atualidade do tema é um aspecto relevante desta pesquisa, visto que o setor portuário está em intensa transformação, com ação de agentes capazes de auferir resultados positivos 
para suporte ao crescimento econômico do país, colocando à disposição das empresas modais de transporte que, se bem aproveitados, podem melhorar a competitividade dos seus produtos.

O trabalho está organizado em cinco capítulos. O primeiro, em apresentação, introduz o tema, sua importância, o objetivo da pesquisa, seu escopo e estrutura. $\mathrm{O}$ segundo traz a revisão de literatura concentrando-se nos temas do processo de reforma institucional dos portos públicos brasileiros desde a implantação da Lei 8.630, a evolução da infraestrutura portuária de contêineres e competição entre operadores portuários, aspectos regulatórios do transporte de cabotagem e entraves para seu desenvolvimento, a consolidação do serviço de cabotagem e a complementaridade dos transportes multimodais. O terceiro capítulo revela a metodologia da pesquisa. O quarto apresenta uma avaliação dos resultados da modernização dos portos, serviços de cabotagem e complementares, ilustrado por dois casos de sucesso no transporte de resinas entre as cidades de Camaçari e Santos e de arroz entre Pelotas e Recife. Finalmente o quinto capítulo é dedicado às conclusões.

\section{REVISÃO DE LITERATURA}

Fleury et al. (2000) afirmam que o elo do transportes pode representar mais de $70 \%$ do custo logístico de uma operação, especialmente quando as distâncias entre origem e destino do bem são elevadas. Neste sentido, a redução do custo de uma operação de cabotagem por contêineres, foco desta revisão de literatura, pode contribuir com significativa adição de valor para diversas cadeias de suprimento.

\subsection{Contexto, motivação, benefícios e riscos da privatização portuária}

De acordo com Oliveira (2006), as pressões oriundas da globalização, provocaram um intenso processo de revisão da eficiência portuária, tendo-se em vista as demandas particularmente geradas pelas empresas exportadoras. Nas últimas décadas, portos em todo o mundo seguiram uma tendência de privatização, com a conseqüente transferência da totalidade ou parte da infra-estrutura portuária do domínio público para o particular.

Baird (1999) propõe vários modelos de privatização portuária observados, que vão desde uma divisão de responsabilidades entre os setores público e privado, envolvendo a propriedade do porto, sua operação e regulação do setor, como ocorreu no Brasil, EUA, Argentina, China, Holanda, Índia, entre outros, até um modelo de total transferência para a iniciativa privada, como ocorreu na Inglaterra.
A privatização portuária foi motivada, segundo Cullinane e Song (2002), primariamente pela expectativa de benefícios econômicos decorrentes da melhor eficiência e também pelo desejo político de se reduzir a responsabilidade governamental pelo financiamento de longo prazo e gestão de uma indústria extremamente cara de se manter. Outros motivadores que, segundo estes autores, são menos importantes, podem ser também apontados, tais como: resolução de atritos na relação governo e sindicatos, promoção do capitalismo, estímulo para o transporte internacional, aumento da competitividade na arena interna, aumento das opções de escolha para o embarcador, aumento de oportunidades de trabalho, dinamização do setor, aumento do potencial de geração de economias de escala e eliminação ou minimização da influência política e burocrática na gestão e operação portuária, entre outras.

Embora seja consensual, para a maior parte dos autores, conforme apontado por Cullinane e Song (2002), que os benefícios primários advindos da privatização portuária são facilmente reportados nas diversas experiências mundiais, deve-se atentar para alguns problemas decorrentes desta prática. $\mathrm{O}$ mais destacável, de acordo com De Monie (1996, apud Cullinane e Song, 2002), é o fato de que, como empresas particulares estão preocupadas com a maximização de seus lucros, elas podem negligenciar cuidados em instalações e serviços que, mesmo sendo socialmente ou ambientalmente essenciais, geram mais custos que vantagens. Esta pressão por lucros, quando encontra uma autoridade portuária fraca pode trazer perdas sociais importantes. Uma segunda preocupação apontada pelo autor é o fato de que a privatização de alguns portos, por suas especificidades de localização, pequena escala operacional ou inadequada rede de transportes terrestres pode converter-se de um monopólio público para outro privado. Um terceiro potencial problema da privatização decorre da falta de coordenação entre a autoridade portuária e o setor privado, que pode gerar desacordos em investimentos e operações, conduzindo a uma redução de eficiência portuária. Finalmente o último problema apontado pelo autor refere-se a uma possível discriminação para os clientes do porto, com benefício explícito para os usuários associados aos interesses dos operadores privados. As duas primeiras preocupações são também compartilhadas por Goss (1998). Preconiza o autor que, dados os potenciais problemas amplamente reconhecidos da privatização portuária, tal processo deve vir fortemente sustentado por um conjunto de medidas regulatórias. 


\subsection{Processo de privatização de portos de carga geral no Brasil}

Antes de 1993, havia duas situações bem distintas no sistema portuário brasileiro. Para cargas a granel, como minério e produtos agrícolas, existia eficiente estrutura de terminais privativos $^{1}$, que operavam exclusivamente carga própria. Para a chamada carga geral, movimentada em contêineres, pallets, sacarias etc, os portos eram estatais, controlados pela Portobrás - Empresa Portos do Brasil S/A e, de forma indireta, pelas Companhias Docas. O sistema portuário de carga geral caracterizava-se pelo controle das tarifas portuárias, pelo monopólio dos sindicatos sobre o fornecimento de mão-de-obra avulsa, pela obsolescência dos equipamentos e falta de investimentos em infra-estrutura, pelo elevado tempo de espera para atracação e de permanência das embarcações no porto. Como conseqüência, os portos públicos apresentavam baixo índice de produtividade, assim como altos custos de operação, principalmente em relação à estiva e aos custos de oportunidade derivados da imobilização de navios. A reversão desta situação exigia volumosos recursos e uma reconfiguração institucional e organizacional dos portos.

O primeiro grande passo no processo de reforma portuária consistiu da extinção da Portobrás, em abril de 1990. O setor de transportes, no âmbito federal, ficou subordinado ao Ministério da Infra-estrutura MINFRA, posteriormente substituído pelo Ministério dos Transportes e Comunicações - MTC e, depois, pelo Ministério dos Transportes - MT. Em 1993, promulgou-se a Lei de Modernização dos Portos, que instituiu um programa de reestruturação da atividade portuária com base em conceitos como desestatização e leis de mercado, extinguindo o monopólio estatal de exploração dos portos e viabilizando uma profunda transformação do sistema de transporte marítimo brasileiro. A lei visava engendrar um ambiente competitivo entre portos de regiões próximas e entre terminais localizados em um mesmo porto, e também criava condições para o aporte de recursos privados. A expansão dos investimentos em infra-estrutura era condição crucial para a retomada das taxas de crescimento da economia. O Estado, embora permanecendo como o detentor da infra-estrutura, passou a não mais atuar como prestador de serviços.

A lei criou a figura do operador portuário que passou a executar os serviços de movimentação e armazenagem de mercadorias destinadas ou provenientes do transporte aqüaviário, realizado na área do porto organizado ${ }^{2}$. Também passou a admitir a movimentação de cargas de terceiros em terminais privativos, criando a figura da 'instalação portuária de uso privativo misto', removendo a restrição estabelecida pela legislação anterior. Foram criados os Conselhos de Autoridade Portuária - CAPs, representados por todos os segmentos econômicos interessados na atividade portuária - Governo, Operadores Portuários, Usuários e Trabalhadores Portuários. Os CAPs atuam como organismos normatizadores e reguladores dos portos, buscando sua promoção e melhoria. Instituiu-se ainda o Órgão Gestor de Mão-de-Obra - OGMO, que regula a relação entre os trabalhadores avulsos e os terminais portuários. A relação capital-trabalho passou a ser subordinada às normas pactuadas em contratos, acordos coletivos ou convenções de trabalho e incentivou a adoção da multifuncionalidade como norma para o novo trabalhador portuário. $\mathrm{O}$ governo, no âmbito das Administrações dos Portos, instituiu planos de incentivo ao desligamento voluntário, que reduziu o quadro de funcionários para $32 \%$ do inicial. (OGMO, 2000).

Em 1995, deu-se início ao processo de arrendamento dos terminais portuários à iniciativa privada. Os contratos e editais em diversos portos apresentaram regras diferentes para obtenção do arrendamento e controle de preços ao usuário. Os portos que já tiveram terminais de contêineres privatizados são Suape, Salvador, Vitória, Rio de Janeiro, Sepetiba, Santos, Paranaguá, Itajaí e Rio Grande. Segundo a ABRATEC (2007), os terminais representados pela associação materializam os efeitos da privatização dos serviços portuários, proporcionando aos seus usuários armadores, exportadores, importadores e clientes da cabotagem maior eficiência e redução dos custos.

\subsection{Transformação da infra-estrutura portuária de contêineres e competição no setor}

Um dos principais efeitos derivados da privatização foi o aumento significativo do nível de investimento por empresas privadas aplicados em equipamentos de movimentação de contêineres nos pátios e cais, obras civis para reforço das estruturas, expansão dos terminais e tecnologia da informação. Tais investimentos geraram maior eficiência, melhor produtividade e conseqüente redução de preços aos clientes. Por exemplo, de acordo com a pesquisa Aquaviários CNT (2002) a redução da média nacional dos custos de movimentação de contêineres foi superior a 50\%, entre 1997 e 2002.

O modal marítimo foi o que mais cresceu nos últimos anos, indicando uma tendência de aumento de sua participação na matriz de transportes, não só no longo curso, mas também com o renascimento da navegação de cabotagem, que em 2007 passa a representar mais de $13 \%$ dos contêineres 
movimentados no Brasil (ABRATEC, 2007). A Tabela 1 mostra a evolução da movimentação de contêineres no Brasil, por porto.

A melhora geral das operações em terminais de contêineres arrendados à iniciativa privada atraiu cargas e novas escalas de armadores. De acordo com a ABRATEC (2007), a produtividade média é de 50 unidades por hora, contra apenas 8 , antes da privatização. Com preços menores e melhor nível de serviço, os terminais privatizados incentivaram o crescimento da navegação de cabotagem, inclusive com preços reduzidos de estiva e praticagem. Após a privatização, a concorrência se acirrou tanto entre terminais de contêineres de dois ou mais portos, que disputam os mercados de carga de uma mesma região, como entre terminais que operam em um mesmo porto organizado.

\subsection{Regulação do transporte de cabotagem e entraves para seu desenvolvimento}

$\mathrm{O}$ mercado de cabotagem no Brasil é restrito às empresas brasileiras de navegação, operando com embarcações de bandeira nacional ${ }^{3}$. As Resoluções 112 e 193 da ANTAQ estabelecem critérios restritivos para o afretamento de embarcação estrangeira por empresa brasileira para navegação na cabotagem, como, por exemplo, a necessidade de informar oficialmente ao mercado sobre a necessidade de determinado tipo de navio. Caso não haja navios brasileiros disponíveis, um navio estrangeiro pode ser afretado ${ }^{4}$. Porém, de fato, os concorrentes sempre oferecerão espaço em seus navios, e o afretamento de navios estrangeiro será vetado.

Sobre o frete cobrado na navegação de longo curso, cabotagem, fluvial e lacustre, incide o AFRMM Adicional ao Frete para Renovação da Marinha Mercante - na entrada no porto de descarga e deve ser recolhido pelo consignatário da mercadoria transportada. A Lei $10 \quad 893 / 04$ define que, na navegação de cabotagem, o cliente deve contribuir com $10 \%$ do frete para o Fundo de Marinha Mercante ${ }^{5}$. Tais recursos são repassados integralmente ao armador para construção ou reparos de navios em estaleiros brasileiros. Caso o AFRMM não seja utilizado pelo armador no prazo de três anos após a data do depósito, o recurso retorna ao Fundo de Marinha Mercante.

A proteção do mercado de cabotagem é uma prática comum no mundo, como afirmam Oliveira Pinto et al. (2007), no entanto, onera o serviço e gera entraves ao seu desenvolvimento, na medida em que dificulta a renovação da frota e traz como conseqüência o seu envelhecimento, como ocorre nos mercados do Brasil e EUA. No caso particular brasileiro, segundo os autores, a dificuldade na renovação da frota esbarra na questão do financiamento, que é feito através do BNDES, uma vez que os estaleiros brasileiros não conseguem cumprir as exigências do Banco por não possuírem patrimônio líquido para suportarem a garantia exigida (130\% do empréstimo) e muitos sustentarem dívida ativa com o Banco. A escassez de navios prejudica o nível de serviço oferecido, cujos principais sintomas são a falta de regularidade e confiabilidade nas rotas (ONO, 2001).

Duas outras questões relevantes no tocante às dificuldades da cabotagem são o desbalanceamento da frota de contêineres e o crescente encarecimento destes, devido ao preço do aço, onerando os fretes da cabotagem. De acordo com Resende, Toledo e Caigawa (2005), o problema do contêiner vazio decorre do desequilíbrio (imbalance) entre entradas e saídas deste equipamento nos portos e constitui um importante problema de logística reversa. Esta descompensação provém das condições da balança comercial de manufaturados (principais usuários de contêineres), do desequilíbrio inerente de alguns portos, com maior fluxo de embarque ou desembarque de contêineres e do perfil da carga gerada ou atraída pelos portos que exigirão contêineres de 20 ou 40 pés.

\begin{tabular}{|c|c|c|c|c|c|c|c|c|c|c|c|c|}
\hline Porto & 1995 & 1997 & 1998 & 1999 & 2000 & 2001 & 2002 & 2003 & 2004 & 2005 & 2005 & $\begin{array}{c}\text { Yariacă } \\
1995-2005\end{array}$ \\
\hline 1 Sartos & 772 & 830 & 888 & 867 & 1.111 & 1.048 & 1.231 & 1.561 & 1.883 & 2.268 & 2.446 & $216,8 \%$ \\
\hline 2 It ajaí & 87 & 118 & 129 & 136 & 171 & 244 & 335 & 467 & 564 & 649 & 693 & $693,6 \%$ \\
\hline 3 Rio Grande & 162 & 212 & 224 & 259 & 321 & 361 & 453 & 545 & 589 & 633 & 575 & $254,4 \%$ \\
\hline 4 Paranaguá & 115 & 139 & 161 & 198 & 253 & 292 & 271 & 310 & 379 & 420 & 488 & $323,1 \%$ \\
\hline 5 Rio de Janeiro & 173 & 203 & 198 & 204 & 218 & 252 & 270 & 321 & 343 & 325 & 335 & $93,8 \%$ \\
\hline 6 Săo Francisco do Sul & 97 & 95 & 117 & 151 & 168 & 176 & 258 & 282 & 276 & 240 & 221 & $128,4 \%$ \\
\hline 7 Vitória & 66 & 59 & 73 & 114 & 91 & 89 & 124 & 139 & 188 & 220 & 250 & $277,2 \%$ \\
\hline 8 Salvador & 58 & 52 & 57 & 79 & 95 & 107 & 135 & 170 & 192 & 223 & 226 & $292,2 \%$ \\
\hline 9 Suape & 20 & 33 & 49 & 39 & 63 & 73 & 109 & 59 & 138 & 176 & 196 & $897,6 \%$ \\
\hline 10 Sepetiba & 0 & 0 & 0 & 0 & 4 & 17 & 19 & 28 & 133 & 186 & 257 & - \\
\hline 11 Peoém & 0 & 0 & 0 & 0 & 0 & 0 & 21 & 66 & 79 & 101 & 113 & - \\
\hline 12 outros & 142 & 176 & 158 & 243 & 292 & 251 & 253 & 225 & 241 & 247 & 227 & $60,5 \%$ \\
\hline Total & 1.692 & 1.918 & 2054 & 2200 & 2787 & 2909 & 3.478 & 4.173 & 5.005 & 5.6888 & 6.027 & 255,396 \\
\hline Yariaçăo Anual & & 13,496 & 7,196 & $11,5 \%$ & 21,796 & 4,496 & 19,596 & 20,096 & 19,906 & 13,796 & 6,096 & \\
\hline
\end{tabular}

*TEU - Twenty-Foot Equivalent Unit - unidade de medida de um contêiner de 20 pés.

Fontes: ABRATEC (2007); Sites dos portos; Dataliner. 
Para ilustrar a situação apresentada pela descompensação da balança comercial, pode ser citado um artigo da Revista Exame, assinado por Jaggi (2004), intitulado "Falta contêiner", em que a autora relata o progressivo déficit de contêineres em decorrência do crescimento acentuado das exportações brasileiras até aquela data. Outro artigo assinado por Gonçalves (2006) intitula-se "Crescimento das importações causa sobra de contêineres nos portos brasileiros". Neste artigo a autora explicita:

"Há cerca de dois anos, o rápido crescimento do comércio exterior brasileiro, principalmente das vendas externas, gerou diversos entraves logísticos, entre eles, a escassez de contêineres. Hoje, com o aumento das importações, a situação é totalmente oposta. O que se observa é um incremento significativo na disponibilidade de contêineres, principalmente de vazios, em diversos portos brasileiros, inclusive em Santos".

\subsection{Impactos da privatização portuária na cabotagem}

Em meados dos anos 90, a navegação de cabotagem de contêiner retomou seu crescimento, principalmente por causa do controle da inflação e pelo processo de modernização e privatização dos portos, colocando-se como uma das alternativas mais econômicas e confiáveis para a movimentação da carga geral no Brasil. Francisco (2005) afirma que a navegação de cabotagem é ideal para transporte de cargas para distâncias superiores a 1000 quilômetros, dadas as necessidades de se cobrirem os custos da operação e de se reduzirem os inconvenientes para troca de modal durante uma viagem. As três empresas que hoje operam na cabotagem iniciaram seus serviços em 1999 - Aliança Navegação, pertencente ao grupo Hamburg Süd, da Alemanha, Mercosul Line, pertencente a Maersk, de capital Dinamarquês e a Log-In - Logística Intermodal S. A. (ex-Docenave), empresa aberta, listada na Bolsa de Valores de São Paulo.

A relevância da cabotagem de contêineres baseia-se em seu maior valor agregado (produtos manufaturados e semimanufaturados), na necessidade de condições técnicas de infra-estrutura para a sua operacionalização de forma eficiente e no seu potencial de crescimento, visto que há grande volume de carga típica da cabotagem no Brasil ainda transportada pelo modal rodoviário. Cerca de $61 \%$ do PIB nacional está concentrado a menos de $300 \mathrm{~km}$ do litoral. Os grandes centros industriais e as maiores aglomerações populacionais estão dentro dessa faixa, criando um fluxo significativo de bens ao longo da costa.

Com a privatização, a melhoria dos serviços portuários imprimiu forte incremento da produtividade nos portos e reduções de preços cobrados aos proprietários de navios. Como conseqüência, os armadores de cabotagem puderam oferecer a seus clientes mais freqüência, regularidade e redução no frete, tornando-se competitivo em relação ao rodoviário. Os navios passam menos tempo nos portos e realizam mais viagens, o que reduz seus custos médios por tonelada transportada, realimentando a redução dos fretes e aumentando a rentabilidade do setor. A Figura 1 mostra o crescimento expressivo da cabotagem no Brasil, nos últimos anos e a Tabela 2 compara este crescimento com a evolução do PIB Brasileiro.

\subsection{Complementaridade do transporte multimodal ao sistema de cabotagem}

Nos últimos anos, após consolidação do uso do contêiner e o processo de privatização dos portos e ferrovias, o mercado de logística avançou em estudos sobre o uso do transporte multimodal, como alternativa e oportunidade para as empresas tornaremse mais competitivas pela redução dos custos. A multimodalidade permite a integração dos diferentes transportes, com operações porta-a-porta, em substituição ao sistema fragmentado porto-a-porto, que não fideliza o cliente. A figura 2 exemplifica o funcionamento de uma operação porta-a-porta.

A lei $9611 / 98$ que dispõe sobre o transporte multimodal de cargas e cria a figura do Operador de Transporte Multimodal (OTM) é um importante avanço regulatório no setor. Entretanto, apesar do transporte multimodal já ser uma realidade para diversas empresas brasileiras, e de haver algumas dezenas de organizações logísticas registradas como

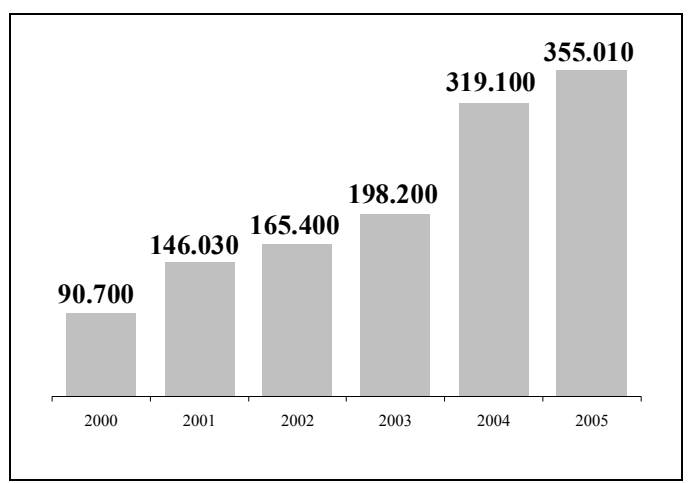

Figura 1: TEUs cheios de cabotagem

Tabela 2: Cabotagem x PIB Brasileiro

\begin{tabular}{ccc}
\hline Ano & $\begin{array}{c}\text { Crescimento da } \\
\text { cabotagem \% }\end{array}$ & $\begin{array}{c}\text { Crescimento do } \\
\text { PIB \% }\end{array}$ \\
\hline 2004 & 62,00 & 5,20 \\
2003 & 20,00 & 0,20 \\
2002 & 13,00 & 1,93 \\
2001 & 61,00 & 1,31 \\
2000 & 281,00 & 4,36 \\
\hline
\end{tabular}


OTM, ainda não se realizou efetivamente uma operação regida por um único contrato de transporte, conhecido como Conhecimento de Transporte Multimodal de Cargas - CTMC, principalmente por razões fiscais sobre cobrança do ICMS. Para emissão do CTMC é necessária a negociação de uma apólice que cubra todo o percurso da carga, o que ainda não se conseguiu até o momento. A figura 3 mostra de que forma o CTMC poderia simplificar o processo documental de uma operação logística, incluindo a cabotagem.

O desenvolvimento da cabotagem multimodal está mais atrelado à combinação com o modal rodoviário, devido a sua grande participação na matriz de transporte brasileira e na sua flexibilidade. Entretanto, os armadores já se aliaram às concessionárias de ferrovias, que oferecem rotas fixas para cargas provenientes da cabotagem, como, por exemplo, entre Santos-Jundiaí, Santos-São Paulo e Santos-Caçapava. A parceria já se estendeu, inclusive, em investimentos compartilhados para aumento da quantidade de vagões.

\section{METODOLOGIA DE PESQUISA}

A pesquisa possui uma abordagem qualitativa, na medida em que se apóia em informações de caráter retórico, obtidas através de entrevistas, vivência dos autores na área e levantamento de dados secundários. Seu propósito é descritivo e exploratório, pois se ocupa de apresentar a evolução de um setor econômico, visando trazer informações relevantes, muitas das quais inéditas, mostrando como a evolução da legislação portuária e o processo de privatização da operação de terminais tornaram economicamente viável e, em muitos casos vantajosa, a navegação de cabotagem por contêineres (Silva e Menezes, 2001).

As fontes de informações primárias foram coletadas de entrevistas não estruturadas com profissionais de notório conhecimento sobre o assunto, envolvendo diretores em terminais de contêineres, armadores e embarcadores. Entre os entrevistados destacam-se o diretor-presidente do TECON Rio Grande, a diretora de logística da Braskem, um diretor da Wilson Sons Logística, o diretor comercial e de logística da Josapar-RS e o diretor do TECON Salvador. As entrevistas foram efetuadas durante o primeiro semestre de 2006 e o roteiro versou sobre aspectos operacionais e custos dos terminais de contêineres, evolução da qualidade do serviço prestado, importância do transporte multimodal no oferecimento de uma solução completa para os clientes e tendências da evolução para o setor. Muitas informações disponíveis em fontes secundárias foram previamente coletadas e estudadas com o objetivo de focalizar melhor a entrevista para o cerne da pesquisa e obter informações mais relevantes sobre a evolução. Também como fonte primária destaca-se a vivência profissional dos autores no setor de transporte marítimo, importante na condução das entrevistas e na

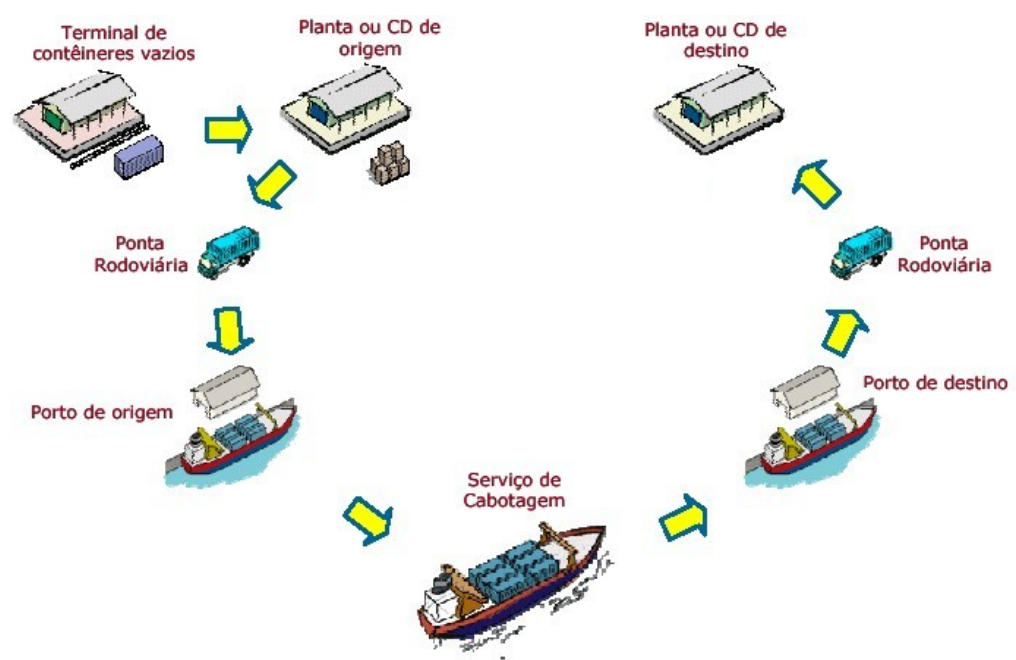

Figura 2: Modelo esquemático da logística porta-a-porta Fonte: Aliança Navegação

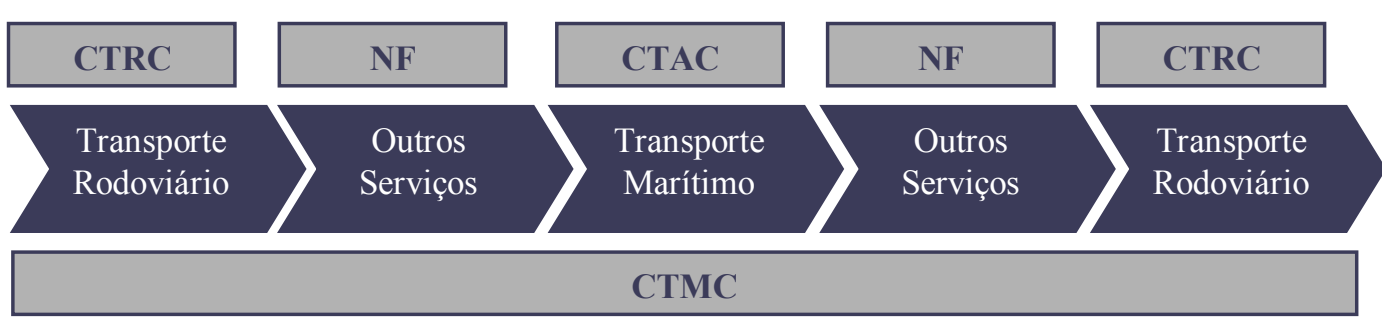

Figura 3: Conhecimento de Transporte Multimodal $x$ documentos atuais Fonte: Elaboração dos autores 
geração de informações complementares ao propósito do artigo. As informações comparativas das situações portuárias antes e depois das privatizações, envolvendo $o$ transporte por cabotagem de contêineres, para resinas e arroz, foram fundamentais na comprovação de como o serviço de cabotagem se tornou viável graças às melhorias e redução de custos nos portos brasileiros após a Lei 8.630.

\section{AVALIAÇÃO DOS RESULTADOS DA MODERNIZAÇÃO DOS PORTOS NOS SERVIÇOS DE CABOTAGEM}

Neste capitulo mostram-se os principais resultados da evolução do transporte de contêineres na navegação de cabotagem a partir do início efetivo da oferta do serviço, após a reforma no setor. No item 4.1 apresentam-se os resultados da compilação das entrevistas com diversos executivos e no item 4.2 mostram-se dois exemplos da viabilização do transporte de contêineres na cabotagem.

\subsection{Avaliação dos principais stakeholders sobre a evolução do transporte de contêineres na cabotagem}

Aspectos operacionais e custos dos terminais de contêineres $-\mathrm{Na}$ opinião de um dos entrevistados:

"O custo do sistema, com a privatização dos portos, foi afetado, pois o preço cobrado para operação de contêineres nos portos foi reduzido pelo significativo ganho de escala obtido pelos terminais, após investimentos maciços em modernos equipamentos, obras civis e sistemas de gestão. Os armadores de cabotagem puderam, então, reduzir seus preços ao cliente final e tornaram-se competitivos em relação ao transporte rodoviário. O aumento de produtividade (contêineres movimentados por hora de operação) apresentado pelos terminais privatizados reduziu o tempo de operação dos navios e o tempo de espera para atracação, o que permitiu a realização de mais viagens por ano".

A fórmula apresentada na Figura 4 mostra a dinâmica para maximização do resultado operacional do serviço de cabotagem.

A partir dessa fórmula, fica fácil identificar que o serviço de cabotagem, para ser viável, depende fortemente da eficiência do setor portuário de contêineres.

Evolução da qualidade do serviço prestado na cabotagem $-\mathrm{Na}$ avaliação de um dos entrevistados:
"O serviço de cabotagem de contêineres enfrentou muita resistência na retomada de suas operações, em meados dos anos 90, por causa da forte cultura de transporte rodoviário nas indústrias, que eram atendidas com grande flexibilidade, rapidez e simplicidade na logística porta-a-porta. Os processos e embalagens eram dimensionados para otimizar as viagens de caminhão e pouco se conhecia sobre o modal marítimo e de que forma a cabotagem surgiria como alternativa viável para o transporte de suas cargas. Por longo período, as empresas de cabotagem enfrentaram dificuldades tentando provar os novos conceitos do serviço e ganhar a confiança do mercado. Com o tempo, no entanto, a postura de seriedade e eficiência dos armadores deu credibilidade à cabotagem".

Segundo a pesquisa CNT sobre cabotagem ${ }^{6}(2002)$, $76,2 \%$ dos usuários acham o serviço bom, 17,7\% regular e $6,2 \%$ ruim. Sobre as principais vantagens da cabotagem levantadas pelos clientes, $88,5 \%$ citou os custos reduzidos do frete, $64,6 \%$ a segurança da carga, $37,7 \%$ a confiabilidade nos prazos e $37,7 \%$ o baixo nível de avarias. A integridade da carga no modal aquaviário foi avaliada positivamente por $93,1 \%$ dos clientes. O resultado geral da pesquisa se deve, em parte, aos investimentos feitos recentemente nos terminais portuários, que gerou redução nos custos portuários e melhoria dos serviços e também à utilização de contêineres por mar, que minimiza os riscos de avaria e roubo das mercadorias. $O$ fator determinante na escolha da empresa de navegação, segundo a maioria os clientes entrevistados $(76,2 \%)$, é o custo do frete, o que pode denotar a homogeneidade percebida pelos clientes com relação à qualidade dos serviços das empresas envolvidas na pesquisa Aliança e Log-In. Entre os clientes que formularam sugestões, $50 \%$ apontam a necessidade de aumentar a freqüência de navios para ampliação do volume.

Importância do transporte multimodal e a solução porta a porta - Um dos executivos entrevistados comenta que:

"Numa primeira fase, os armadores voltaram esforços para comprovar a confiabilidade dos serviços em relação à segurança da carga, qualidade da mercadoria após o transporte e regularidade dos serviços. Numa segunda fase, foi necessário entender todo o processo logístico de cada cliente e oferecer, não só o transporte marítimo porto-a-porto, mas os serviços logísticos complementares, incluindo transporte de ponta das mercadorias, estufagem de contêineres e armazenagem. O

\begin{tabular}{|cccccccc|}
\hline $\begin{array}{c}\text { Resultado } \\
\text { operacional }\end{array}$ & $=$ & $\begin{array}{c}\text { Margem unitária } \\
\text { (USD/TEU) }\end{array}$ & $\mathbf{x}$ & $\begin{array}{c}\text { Volume por viagem } \\
\text { (TEU/Viagem) }\end{array}$ & $\mathbf{x}$ & $\begin{array}{c}\text { Produtividade } \\
\text { (Viagens/ano) }\end{array}$ & $\begin{array}{c}\text { Custo do } \\
\text { Sistema }\end{array}$ \\
\hline
\end{tabular}

Figura 4: Fórmula de cálculo do resultado operacional do serviço de cabotagem Fonte: Log-In (2007) 
crescimento do serviço viabilizou o incremento de oferta de espaço ao longo dos anos".

Este último comentário pode ser evidenciado na Tabela 3.

Tendências da evolução para o setor - A Aliança, atualmente, é o maior armador que opera na cabotagem, com maior oferta de espaço nos navios que seus concorrentes. Como o mercado ainda possui demanda reprimida, a capacidade de transporte é fator chave para definição do market share. Como a Aliança é a única armadora que vem aumentando sua frota gradualmente, tem expandido sua participação no mercado. Dado o potencial deste modal de transporte, a tendência é que o serviço cresça ainda mais. De acordo com um estudo do IPEA (Neto e Santos, 2005), o potencial de crescimento da cabotagem é de cerca de dez vezes o valor transportado em 2004 (R\$ 31 bilhões), podendo chegar a R\$ 311 bilhões, já considerando o potencial de carga de transbordo, que segundo o estudo pode alcançar R $\$ 50$ bilhões.

Na opinião de um executivo ouvido:

"O serviço feeder (carga de transbordo), que liga os $h u b$ ports aos demais portos na região, funciona como uma extensão de linhas de grandes armadores internacionais. $\mathrm{O}$ incremento desse serviço é uma tendência do mercado, visto que, para obtenção de ganho de escala e realização de mais viagens por ano, a nova geração de navios porta-contêineres de grande porte deve concentrar suas escalas em poucos portos eficientes. Com isso, o serviço feeder tem grande potencial de crescimento, como serviço complementar".

As três empresas que hoje operam na cabotagem, também prestam serviço feeder, mas o volume ainda é pequeno. Porém, a regulação do serviço feeder é a mesma da cabotagem, com restrição de uso de navios de bandeira brasileira, e também se defronta com a limitação de capacidade de transporte pela falta deste tipo de navio.

\subsection{Exemplos da viabilidade da cabotagem após a privatização dos portos}

Para apresentação da viabilidade da navegação de cabotagem após o processo de privatização dos portos, foram analisados dois casos: i) Distribuição de resinas de Camaçari (BA) para São Paulo (SP) com contêineres de 40', utilizando os portos de Salvador e Santos e ii) Transporte de arroz de Pelotas (RS) para Recife (PE), com contêineres de 20' utilizando os portos de Rio Grande e Suape.

O estudo foi feito com dados de produtividade, tempo de espera para atracação e média de contêiner por escala com base no serviço realizado pela Log-In. As informações de preço cobrado pelo handling dos contêineres nos portos é uma estimativa da média cobrada aos armadores de cabotagem. A tabela 4 resume as informações de produtividade, tempos de espera e manuseio para cálculos comparativos antes e depois da privatização e a tabela 5 revela o preço de frete porta-a-porta comparativo dos armadores de cabotagem e das empresas de transporte rodoviário "puro".

Com base nos dados da tabela 4, foram analisados os custos que seriam adicionados ao serviço de cabotagem, caso os terminais portuários apresentassem as mesmas condições anteriores ao processo de privatização. Para o cálculo, utilizou-se como premissa o valor diário de afretamento de um navio típico conteineiro de US\$ 18.000,00 (Clarkson, 2006). O custo por hora do navio, portanto, é de US\$ 750,00 .

Na tabela 6 são apresentados, para os quatro portos analisados nos dois casos práticos, os custos a serem adicionados ao preço atual da cabotagem, referente a tempo de espera para atracação, produtividade e movimentação de contêineres, caso os terminais ainda apresentassem o cenário anterior a Lei 8.630/93. Os valores totais na última coluna correspondem à soma para a mesma variável nas ligações analisadas, ou seja, Salvador-Santos e Rio Grande-Suape.

Para cálculo do custo adicional por escala, multiplicou-se a diferença em horas de espera para atracação antes e depois da privatização e o valor de custo de afretamento por hora do navio. Para chegar ao custo adicional por contêiner, dividiu-se o custo adicional por escala pela quantidade média de contêineres movimentado por escala em cada porto. As horas de operação antes e depois da privatização são calculadas a partir da divisão da quantidade média de contêineres movimentados no porto, por escala,

Tabela 3: Evolução da capacidade estática na cabotagem e de market share

\begin{tabular}{|c|c|c|c|c|c|c|c|c|c|c|c|c|c|c|c|}
\hline & \multicolumn{3}{|c|}{2001} & \multicolumn{3}{|c|}{2002} & \multicolumn{3}{|c|}{2003} & \multicolumn{3}{|c|}{2004} & \multicolumn{3}{|c|}{2005} \\
\hline & Navios & Slots & Share & Navios & Slots & Share & Navios & Slots & Share & Navios & Slots & Share & Navios & Slots & Share \\
\hline Aliança & 2 & 1900 & $40 \%$ & 3 & 2790 & $39 \%$ & 3 & 2790 & $45 \%$ & 4 & 6190 & $55 \%$ & 7 & 10990 & n.d. \\
\hline Docenave & 5 & 2820 & $42 \%$ & 5 & 2820 & $42 \%$ & 5 & 2820 & $31 \%$ & 5 & 2820 & $27 \%$ & 5 & 2820 & n.d. \\
\hline Mercosul Line & 2 & 2000 & $18 \%$ & 2 & 2000 & $19 \%$ & 2 & 2000 & $24 \%$ & 2 & 2000 & $18 \%$ & 2 & 2000 & n.d. \\
\hline Total & 9 & 6720 & $100 \%$ & 10 & 7610 & $100 \%$ & 10 & 7610 & $100 \%$ & 11 & 11010 & $100 \%$ & 14 & 15810 & $0 \%$ \\
\hline
\end{tabular}

Slot: Espaço no navio ocupado por 1 TEU

Fonte: Empresas de Cabotagem 
Tabela 4: Indicadores dos portos antes e depois da privatização

\begin{tabular}{|c|c|c|c|c|c|c|c|c|c|c|}
\hline \multirow{2}{*}{\multicolumn{2}{|c|}{ Porto }} & \multirow{2}{*}{\multicolumn{3}{|c|}{$\begin{array}{c}\text { Média de movimentos } \\
\text { por escala }\end{array}$}} & \multicolumn{3}{|c|}{ Antes da privatização } & \multicolumn{3}{|c|}{ Após a privatização - 2005} \\
\hline & & & & & $\begin{array}{l}\text { Espera para } \\
\text { atracação } *^{1}\end{array}$ & $\begin{array}{l}\text { Produtividade } \\
\text { média }^{* 1}\end{array}$ & $\begin{array}{c}\text { Preço por } \\
\text { contêiner }^{* 3}\end{array}$ & 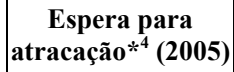 & $\begin{array}{l}\text { Produtividade } \\
\text { média } * 4\end{array}$ & $\begin{array}{c}\text { Preço por } \\
\text { contêiner* }\end{array}$ \\
\hline Sigla & Nome & cheios & vazios & total & Horas & Cntr/hora & & Horas & Cntr/hora & \\
\hline RIG & Rio Grande & 205 & 177 & 382 & 14,4 & 10,0 & USD 409 & 3,4 & 36,0 & USD 159 \\
\hline SUA & Suape ${ }^{* 2}$ & 252 & 137 & 389 & 11,1 & 10,0 & USD 386 & 5,0 & 23,0 & USD 209 \\
\hline SSZ & Santos & 133 & 52 & 185 & 22,0 & 8,0 & USD 315 & 12,2 & 16,0 & USD 257 \\
\hline SSA & Salvador & 174 & 118 & 292 & 12,0 & 8,0 & USD 261 & 5,9 & 33,0 & USD 157 \\
\hline
\end{tabular}

${ }^{* 1}$ : Fonte ABRATEC (2007)

*2: O porto de Suape só iniciou suas operações após o processo de privatização, em 2002. Neste caso, os dados relativos ao período de "antes da privatização" refere-se ao porto público de Recife.

*3: Preços correspondem à tarifa média cobrada aos armadores de cabotagem de operação portuária por contêiner em Real, convertido para dólar a base de US\$1 = R $\$ 2,20$.

*4: Espera e produtividade média com base nos dados da Log-In em 2005.

Tabela 5: Frete porta-a-porta (R\$ por contêiner)

\begin{tabular}{lccc}
\hline & $\begin{array}{c}\text { Cabotagem + pontas } \\
\text { rodoviárias }\end{array}$ & Rodoviário & $\begin{array}{c}\text { Frete rodoviário } x \\
\text { marítimo porta a porta }\end{array}$ \\
\hline Camaçari/ São Paulo & $\mathrm{R} \$ 4.300$ & $\mathrm{R} \$ 4.630$ & $7,7 \%$ maior \\
Pelotas/ Recife & $\mathrm{R} \$ 6.400$ & $\mathrm{R} \$ 6.800$ & $6,3 \%$ maior \\
\hline
\end{tabular}

Tabela 6: Custos adicionais referentes a tempo de espera para atracação, produtividade e movimentação de contêineres para os portos de Salvador, Santos, Rio Grande e Suape

\begin{tabular}{|c|c|c|c|c|c|c|c|}
\hline Porto & Variável & $\begin{array}{c}\text { Antes da } \\
\text { Privatização }\end{array}$ & $\begin{array}{l}\text { Depois da } \\
\text { Privatização }\end{array}$ & Diferença (horas) & $\begin{array}{l}\text { Custo Adicional } \\
\text { por Escala (US\$) }\end{array}$ & $\begin{array}{l}\text { Custo Adicional } \\
\text { por Contêiner } \\
\text { (US\$) }\end{array}$ & Total (US\$) \\
\hline \multirow{3}{*}{ Salvador } & Espera para atracação (horas) & 12,0 & 5,9 & 6,1 & $4.575,00$ & 15,67 & \\
\hline & Tempo de Operação (horas) & 36,5 & 8,8 & 27,7 & $20.738,64$ & 71,02 & \\
\hline & Manuseio (US\$) & 261,00 & 157,27 & n.a. & n.a. & 103,73 & \\
\hline \multirow{3}{*}{ Santos } & Espera para atracação (horas) & 22,0 & 12,2 & 9,8 & $7.350,00$ & 39,73 & 55,40 \\
\hline & Tempo de Operação (horas) & 23,1 & 11,6 & 11,6 & $8.671,88$ & 46,88 & 117,90 \\
\hline & Manuseio (US\$) & 315,00 & 256,82 & n.a. & n.a. & 58,18 & 161,91 \\
\hline \multirow{3}{*}{ Rio Grande } & Espera para atracação (horas) & 14,0 & 3,4 & 11,0 & $8.280,00$ & 21,68 & \\
\hline & Tempo de Operação (horas) & 38,2 & 10,6 & 27,6 & $20.691,67$ & 54,17 & \\
\hline & Manuseio (US\$) & 409,00 & 159,09 & n.a. & n.a. & 249,91 & \\
\hline \multirow{3}{*}{ Suape } & Espera para atracação (horas) & 11,1 & 5,0 & 6,1 & $4.545,00$ & 11,68 & 33,36 \\
\hline & Tempo de Operação (horas) & 38,9 & 16,9 & 22,0 & $16.490,22$ & 42,39 & 96,56 \\
\hline & Manuseio (US\$) & 386,00 & 209,1 & n.a. & n.a. & 176,91 & 426,82 \\
\hline
\end{tabular}

pela produtividade média de contêineres movimentados por hora.

Nos cálculos comparativos entre os transportes multimodal, envolvendo a cabotagem, e o transporte puramente rodoviário, não foi levada em conta a diferença de custo de imobilização da carga, relacionada aos diferentes tempos de estufagem de contêiner, transportes, transbordos e esperas para embarcação, que penalizaria a opção multimodal, especialmente pelo maior tempo de espera pelo modal marítimo. Estima-se que o maior tempo de ciclo para o transporte multimodal impacte, sobretudo, os estoques de segurança, que implicaria em um maior capital imobilizado na opção multimodal. Por falta de informações, no entanto, esta apuração não foi realizada.

Transporte de Resinas entre Camacari (BA) e São Paulo (SP)

A diferença de preço por contêiner movimentado é encontrada diminuindo-se o preço de operação de um contêiner antes e depois da privatização. Logo, o custo adicional total na rota entre Camaçari e São Paulo seria de US\$ 335,20, que convertidos ao Real (US\$ 1 $=\mathrm{R} \$ 2,20)$ corresponderia a $\mathrm{R} \$ 737,45$ a mais no ciclo - incremento de $17,15 \%$ no custo atual. O valor do frete porta-a-porta da cabotagem passaria de $\mathrm{R} \$$ $4.300,00$ para $\mathrm{R} \$ 5.037,45$, o que representaria um custo $8,8 \%$ acima do frete rodoviário apresentado na tabela 5, de R\$ 4.630,00.

Para ilustrar este caso, tomemos como exemplo o depoimento da diretora de logística da Braskem, maior petroquímica da América Latina:

"Ao longo dos anos, a empresa vem alterando gradativamente a logística de suas cargas, aumentando a participação dos modais marítimo de cabotagem e ferroviário na distribuição interna de seus produtos. Para a diretora de logística da empresa, a adoção de diferentes modais de transporte foi possível pela melhoria dos serviços implantados pelas arrendatárias das infra-estruturas 
de portos e ferrovias. Por conseqüência, empresas armadoras de cabotagem puderam consolidar seus serviços. O transporte rodoviário que domina a movimentação de cargas da empresa tem perdido espaço para a cabotagem em decorrência do menor custo de frete, menor incidência de avaria na carga, e eliminação de roubos e acidentes que ocorre no transporte rodoviário. Cerca de $12 \%$ do volume distribuído pela empresa é transportado pela cabotagem, nas rotas entre Maceió-São Francisco do Sul, Salvador-São Paulo, entre outras".

Transporte de Arroz entre Pelotas (RS) e Recife $\underline{(\mathbf{P E})}$

Para este caso, o custo adicional total na rota entre Pelotas e Recife seria de US\$ 556,74 que convertidos ao Real (US\$ $1,00=\mathrm{R} \$ 2,20$ ) corresponderia a R\$ $1.224,82$ a mais no ciclo. $\mathrm{O}$ custo da navegação de cabotagem neste trecho passaria de $\mathrm{R} \$ 6.400,00$ para $\mathrm{R} \$ 7.624,82$ - 12,13\% acima do frete rodoviário “puro" de R\$ 6.800,00.

Para ilustrar este caso de viabilidade da cabotagem a partir da privatização dos portos, temos a situação da Josapar. A empresa situa-se no Rio Grande do Sul, sendo a maior beneficiadora de arroz da América Latina. Sua principal linha de produto é o arroz Tio João, líder no mercado nacional. No depoimento de seu diretor comercial e de logística:

“A Josapar passou a utilizar o modal marítimo de cabotagem após a privatização dos portos. Atualmente, entre $15 \%$ e $20 \%$ da carga distribuída no mercado interno é transportado via cabotagem. O serviço atende a demanda do cliente com qualidade e menor custo quando a carga tem como destino os portos da região Nordeste. Entretanto, ainda faltam opções para o norte do país, como Belém, por exemplo, onde a única armadora de cabotagem a escalar o Porto de Vila do Conde, próximo a Belém, é a Aliança Navegação. A redução de custo percebida pela Josapar com a transferência da carga do modal rodoviário para o marítimo é de cerca de $20 \%$. A empresa vê vantagens na possibilidade de transporte de grandes volumes por vez, o que simplifica sua distribuição. Grande parte da carga ainda é transportada por rodovia, pois a empresa distribui significativa parcela de seus produtos para cidades afastadas da região portuária”.

\section{CONCLUSÕES}

A Lei 8.630/93 representou um grande avanço ao sistema de terminais de contêineres, dentre as quais se destacam a modernização de instalações e de equipamentos, reforma e atualização da legislação portuária e adequação da força de trabalho às demandas efetivas. Embora relevante, este último item não foi focalizado pela pesquisa. Como conseqüências imediatas houve aumento da produtividade das operações, redução significativa dos custos portuários, aumento substantivo do volume de contêineres movimentados e retomada da navegação de cabotagem de contêineres. O forte incremento da produtividade significou menos tempo de espera para atracação, operação mais rápida e mais viagens realizadas por ano, gerando, assim, maior otimização do navio. Com o ganho de escala obtido pelos terminais e conseqüente incremento de volume, os preços de operação portuária foram reduzidos, impactando positivamente na diminuição dos fretes marítimos de cabotagem, que se tornaram competitivos em relação ao rodoviário, seu maior concorrente. O melhor nível de serviço prestado pelos terminais garante a regularidade das operações e, conseqüentemente, dos prazos de entrega aos clientes da cabotagem.

De modo geral, a visão dos usuários de cabotagem relatada no estudo, mostra que os arrendamentos portuários foram bem sucedidos. Os casos analisados de clientes revelaram que o modal aqüaviário apresenta vantagens significativas em relação ao transporte rodoviário no que diz respeito ao custo do frete, segurança da carga, confiabilidade nos prazos e redução da avaria da carga. A melhor opção para suprir a falta de capacidade de transporte é o incentivo e facilitação à construção de navios.

Com o crescimento sustentado da cabotagem e consolidação do serviço, os próprios armadores passaram a disponibilizar, não só o transporte marítimo porto-a-porto, mas também o porta-a-porta, oferecendo, desta forma, mais do que um serviço de transportes, a solução do problema para os embarcadores, como faz seu principal concorrente, o modal rodoviário. Há, ainda, a possibilidade de crescimento da cabotagem como sistema alimentador de cargas entre portos concentradores $-H u b$ ports $-\mathrm{e}$ portos regionais, visto que a tendência do transporte marítimo internacional é a operação de navios de grande porte, com escalas restritas a poucos portos para otimização dos ativos e alcance de ganhos de escala.

Os investimentos privados em terminais portuários não foram acompanhados pela melhora da infraestrutura pública, principalmente das vias de acesso terrestre e marítima. Há também problemas de excessivo assoreamento e falta de dragagem que impedem a escala de navios de maior calado, o que geraria ganhos de escala. Para complementar o avanço obtido com os arrendamentos portuários, é imperativo que a infra-estrutura pública, principalmente os acesso aos portos e as dragagens, recebam investimentos e sejam adequada às necessidades de cada porto. Outro fator que merece destaque é a necessidade de maior coordenação entre as autoridades públicas que se envolvem com a operação em cada porto, muitas 
vezes gerando procedimentos burocráticos e superpostos que atrasam as operações dos navios, reduzindo a produtividade dos portos.

\section{REFERÊNCIAS BIBLIOGRÁFICAS}

ABRATEC. Associação Brasileira de Terminais de Contêineres de Uso Público. Desempenho 2006. Disponível em: http://www.abratecterminais.org.br/novo/default.asp. Data de acesso: 18 de outubro de 2007.

Baird, A. J. A Privatização dos Portos na Grã-Bretanha. In: Gerardo Silva e Giuseppe Cocco (Orgs.). Cidades e portos: os espaços da globalização. Rio de Janeiro: DP\&A, 1999.

CLARKSON RESEARCH STUDIES. Contêiner Intelligence Monthly. Volume 8, no. 3, Março de 2006. ISSN: 1467-0488. Disponível em: $<$ http://85.92.194.89/pubs/pubs.asp?pOpt=current\&pSel=curr ent\&pub $=$ CIMO\&title =Contêiner+Intelligence + Monthly $>$. Acessado em: 3 de abr. 2006.

CONFEDERAÇÃO NACIONAL DOS TRANSPORTES (CNT). Pesquisa Aqüaviários CNT - 2002: Relatório Analítico - portos, cabotagem e navegação interior. Maio de 2002.

Cullinane, K. e Song, D. Port Privatization policy and practice. Transport Reviews, v. 22, n. 1, p. 55-75, 2002. ISSN 0144-1647.

Fadda, E. A. Opções de Política para o Desenvolvimento da Cabotagem Brasileira. $17^{\circ}$ Congresso Nacional de Transportes Marítimos, Construção Naval e Off-Shore. Rio de Janeiro: Sobena, BNDES, set. 1998. Disponível em: <http://www.transportes.gov.br/bit/ estudos/cabotagem/opcoes-politica.pdf $>$. Acessado em: $20 \mathrm{de}$ fev. 2006.

Fleury, P. F.; Wanke, P.; Figueiredo, K. (Organizadores). Logística Empresarial - A perspectiva Brasileira. São Paulo: Atlas, 2000.

Francisco, M. De vento em popa. Desafios do desenvolvimento - Revista Mensal de Informações e Debate do Ipea e do Pnud. Edição 17 Dezembro/2005. Disponível em <http://www.desafios.org.br/ Edicoes/17/artigo13695-1.asp>. Acessado em: 24 de fev. 2006.

Gonçalves, M. C. Crescimento das importações causa sobra de contêineres nos portos brasileiros. NetMarinha. 11 abr. 2006. Disponível em: $<$ http://netmarinha.uol.com.br/setores.asp? $\mathrm{Ct}=$ dir $\& I d=9332 \&$ Area=logistica. Acessado em: 26 abr. 2008.

Goss, R. British Ports Policies since 1945. Journal of Transport Economics and Policy, v. 32, prt1, p. 55-71, 1998

Jaggi, M. Falta Contêiner. Revista Exame, São Paulo, 30 fev. 2004

Neto, C. A. S. C.; Santos, M. de B. Perspectivas do crescimento do transporte por cabotagem no Brasil. Texto para discussão n. 1129. Brasília: Ipea, out 2005.

OGMO - Órgão Gestor de Mão-de-Obra. Competência $e$ Responsabilidade dos OGMOs. Comissão Portos. Brasília, Agosto de 2000. Disponível em: <www.ogmo.gov.br>. Acessado em: 15 out. 2006

Oliveira Pinto, M. M.; Colin, E.C.; Favarin, J.V.R., Akao; D.R.P.L.; Anderson, V.L. Legislação de cabotagem no Brasil: Oportunidades e entraves para a indústria de construção naval. In: Congresso Ibero-Americano de engenharia naval. São Paulo, 2007. COPINAVAL'2007. São Paulo: IPIN, 2007.

Oliveira, R. N. O processo de privatização do Porto de Santos e o Terceiro Setor. 2006. Dissertação (Mestrado em Gestão de Negócios). Universidade Católica de Santos, Santos, 2006.

Ono, R. T. Estudo de viabilidade do transporte marítimo de contêineres por cabotagem na costa brasileira. 2001. 132 p. Dissertação (Mestrado em Engenharia Naval). Programa de Engenharia Naval. Escola Politécnica da Universidade de São Paulo, São Paulo, 2001.

Resende, L.B.; Toledo, L.A.; Caigawas. M. Proposta de modelo de apoio ao reposicionamento e leasing de contêineres em navios. Revista da FAE, Curitiba, v. 8, n. 2, p. 29-51, 2005.

Silva, E. L.; Menezes, E. M.. Metodologia da Pesquisa e Elaboração de Dissertação. $3^{\text {a }}$. edição ver. Atual. - Florianópolis: Laboratório de Ensino a Distância da UFSC, 2001.

Souza, A. G. R. A visão da ANTAQ para a melhoria do mercado portuário. Palestra proferida pelo superintendente de Portos da ANTAQ no Congresso de Pesquisa e Ensino em Transportes XVIII ANPET. Florianópolis - SC - 09 de novembro de 2004.
${ }^{1}$ Os terminais de uso privativo são aqueles localizados fora da área do porto organizado. Como uma das principais vantagens, estes terminais não são obrigados a requisitar trabalhadores portuários avulsos.

${ }^{2}$ Entende-se por porto organizado aquele concedido ou explorado pela União, cujo tráfego e operações portuárias estejam sob jurisdição de uma autoridade portuária.

${ }^{3}$ A autorização para armadores de cabotagem no Brasil é concedida pela ANTAQ. Pode ser obtida por pessoa jurídica que possui pelo menos uma embarcação de bandeira brasileira (própria ou afretada a casco nu), patrimônio líquido mínimo de R\$ 6 milhões e índice de liquidez corrente igual ou superior a 1 .

${ }^{4}$ Procedimento conhecido como circularização.

${ }^{5} \mathrm{Na}$ navegação de longo curso, o AFRMM é de $25 \%$ sobre o frete pago.

${ }^{6}$ Pesquisa com 162 usuários dos serviços da Aliança e da Log-In, realizada entre os dias 30/04/2002 e 9/05/2002. 